\title{
Some perception on Open management of university Electronic Reading Rooms
}

\author{
Guocui Li \\ Library, Linyi University, 276005, China
}

Keywords: Colleges and universities. Electronic reading room. Open management

\begin{abstract}
The Open management of Electronic Reading Room of university library can not only keep the good management idea of traditional Library Reading room, but also should conduct continuous innovation according to the features of openness. Therefore, the administrators in the university and college Electronic Reading Room should carry out open type management by all kinds of measures, thereby provide the readers with better service. This paper expounds the main condition of the essential condition favorable to the open type management of the Electronic Reading Room, and put forward several countermeasures to appropriate for it.
\end{abstract}

\section{Introduction}

With the rapid development of network technology worldwide, information resources keep spreading widespread in new ways. In order to adapt to the development trend of the network era, libraries in colleges and universities began to set up the multifunctional electronic reading room in colleges and universities combining the information consultation, video search and other informatization service, with the resources of computers, database and network communication there exist major shift in the content and form in Electronic Reading Room which differs from traditional reading room, and changes the malpractice of independent library institutional framework and single printed form library mode, thereby providing the reading public with convenient and accurate service through computer network Through the implementation of the open management, the room resources become more abundant, widening the resource source range provided by library, from the traditional books and newspapers and periodicals to E-journal and all classes of network info , diversifying the room resource, widening the range from the primary reality depository to the virtual one, and promote the effectiveness of retrieval. At this point, the author will discuss the open management of university Electronic Reading Rooms.

\section{The essential conditions in which Electronic Reading Room realize open management}

So-called the open management in Electronic reading room refers to that reader can conduct the activities such as inquiry and reading without administrative personnel in the open time scale. Electronic reading room must meet the following conditions if they want to realize open management,

\section{Strengthen the hardware configuration of electronic reading room.}

Electronic reading room mainly includes the corresponding number of computer equipments, displays, host computer, keyboard and mouse, etc., some of which are even equipped with ear plugs. In order to strengthen the powerful technical support to the normal operation of computer in the electronic reading room, which need to be equipped with central control server and switchboard, etc? In order to facilitate the readers to use the electronic reading room in the open type, we can deploy the public printer, for the readers to print on their own. The installation and wiring of power outlet, power cords and cables must conform to the requirements of the fire prevention work. the Electronic Reading Room in the university library often have large sizes, and a reading room often has one hundred and more computers with more users and high turnover rate. Once the time used is too long, the power cord must bear the load. Electronic reading room in colleges and universities should serve the center of scientific research in colleges and universities, as a result, and have very strong 
technicality. Taking this into consideration, it is very important to strengthen the construction of university library website. Electronic resources can be said to be very important in the construction of university library website. Because the appropriation of Electronic Reading Room in university and college is quite limited, which need to make the best of precious funds, focusing on the introduction of the high quality electronic resources, thereby meet the readers' own demands for instance, university Electronic Reading Rooms may introduce database of CNKI ,VIP database , Wanfang Data, etc. and should introduce the database such as sciencedirect, springerlink and biosis preview database, etc. the above inclusive electronic resources can inevitably meet the requirement of the teacher and student in university and college in independent consultation. At the same time, open electronic reading room can also upload the optical disk to the server of the Electronic Reading Room, for downloading individually by teacher and student In view of quite a lot of users of Electronic Reading Room, a large number of teachers and students can download information with compact disk, U disk or MP3, in so doing create virus to be prevalent, therefore, it's necessary to install better -performance anti-virus software, thereby guaranteeing the normal operation of the computers.

Improve the environment and sanitary condition in electronic reading room.

Given the longer time of the open Electronic Reading Room, and more computers, causing greater radiation, therefore, Electronic Reading Room must keep well ventilated, and meet the requirement in indoor temperature and humidity put forward by computer s, therefore, where some central air conditioning, powerful vertical air conditioning should be installed which can deal with the local weather through the functions such as air supply, drying and refrigeration. At the same time, due to the large number of computer users and higher turnover rate, personnel should carry out the disinfection work, do some cleaning frequently, and thereby keep the internal environment of the Electronic Reading Room clean and tidy.

\section{Pay attention to the staffing of the Electronic Reading Room}

Open Electronic Reading Room of the library has very high technique content, which requires the staff with responsibility and proficiency in computer operation to take charge of the routine work of the Electronic Reading Room. In particular, it's necessary that the personnel with specialized computer technology should take charge of maintenance of the computers, and the personnel with computer software design skill should carry out the website construction and perfecting work of the library website. regulatory regime of the Electronic Reading Room in the library should be worked out In order to let the reading public and staff to have a legal basis , implement the supplement and consummation according to new problems, thereby guaranteeing the normal operation of the various facilities , and guarantee that open management can be carried out normally.

\section{Several countermeasures appropriate for open management of the university Electronic Reading Rooms}

\section{Throw money to improve the hardware and software configuration of electronic reading room.}

The electronic reading room in colleges and universities can provide the readers with the various types of electronic data. The content of this multimedia information is very rich, and mostly abundant and elegant, vivid and lovely, which is well received in the reader. Electronic reading room primarily provides the teachers and students with abundant electronic resources. There is no denying that, however, the maintenance of the computers in the Electronic Reading Room requires large sums of money. Therefore, the administrators in the Electronic Reading Room should apply actively for special-purpose funds, and earmark the fund for its specified purposes only to use the money to buy computers and its accessories heart and soul, thereby meeting the need of open management. Because the number of equipment purchased is larger, it's necessary to implement open bidding and tendering, acquire the favorable price through comparing goods, thereby obtaining top-quality electronic products. Electronic Reading Room in the University library differ completely from the internet cafe, not targeting at earning profit, however, it's obligatory to maintain the computers, especially after the implementation of the open management, on the other hand, the damage ratio of the equipment is 
even higher, therefore requiring to invest corresponding capital. at the same time, maintenance funds Allocated by universities are quite limited, which require administrators to plan carefully, arrange funds rationally, to improve the software and hardware equipment in the Electronic Reading Room, and conduct Careful maintenance of computers.

\section{Carry out the automatic remote service}

administrative personnel of the library in Colleges and universities can conduct real time, convenient and high performance automated management and monitoring through machine room management information system, smooth the way for implementing the open management, thereby solving the problems in computer time statistics, network monitoring, remote control and resource sharing The relatively popular management information of machine room utilize the intellectualization navigation design mode, with complete and steady functions, easy to maintain and widen, capable of providing monitoring for Electronic Reading Room administrative personnel can shut down, restart, cancel, register, reregister sell the computer s in the Electronic Reading Room , and sending related information to readers, very suitable for open management.

\section{The integration of preponderant human resources}

The electronic reading room in colleges and universities need the experts on computer to engage on management, not only can introduce the high quality talent major in computer, but also encourage the personnel in university library to strengthen the learning of the new knowledge and new skills. The administrative personnel in the university Electronic Reading Rooms should possess strong responsibility; know the various operations related to computer, especially to be familiar with the operation flow of the service machine. So-called work machine mainly refers to the central control computer, often have the specific functions such as fee charging, real-time monitoring the operational state Managers must be careful in the process of charging, and should correct it in time if they find errors and omissions it's indispensable in the modern university to obtain related document information on network, communicate, chat, make friends and play, which also epitomizes the progress of current era. With regard to the above requirements, university Electronic Reading Room can't provide good service that can kill the university students' strong interest to Electronic Reading Room, who will turn to internet cafe around the universities. the author thinks, educational institution had no means of effective management and guidance of students who go on the Internet in the Internet cafe the universities might as well let the students carry out entertainment activities in the safe and reliable library, thereby more favorable to management, and as a result of the open management, students may take advantage of network resources without control. therefore, university Electronic Reading Room may open some functions so as to pull back the students from the extramural internet cafe instead of refusing the readers to conduct entertainment activity At the same time, the monitoring function of working machine in electronic reading room in colleges and universities can give full play in face of miscellaneous network info, for example, once you find that the readers are browsing unhealthy network info, you can deliver message as a reminder, the student who refuses to mend his ways can be forced to be off-line. This requires that management personnel to possess elementary knowledge, elementary knowledge of computer operation, the ability of computer simple trouble shooting answer the problems put forward by s students, thereby be adequate to open management of Electronic Reading Room in the library.

\section{Improve the rules and regulations of open management in Electronic Reading Room}

In order to adapt to the needs of the open management of electronic reading room, the strict rules and regulations must be worked out, and resentful management move must be adopted, which is the important system assurance to promote the service quality of university and college Electronic Reading Room. The difference between university and college Electronic Reading Room and other reading room is that it is equipped with a large number of advanced technology equipment; this would require the application of new management style. The scientific, reasonable and feasible detailed rules and regulations must be established, making readers and staff has a legal basis, which requires welling maintaining the equipment in the university Electronic Reading Rooms. The users must comply with the related laws and regulations in the use of the network instead of conducting the activities involved in harming the national security, it is forbidden to browse the harmful 
information such as obscenity and violence, talking loudly is not allowed. At the same time, the regulatory regime about open Electronic Reading Room, notice to reader of open Electronic Reading Room and the responsibility of the personnel of open Electronic Reading Room should be established and implemented. Only real establishment of a set of effective rules and regulations about Electronic Reading Room may truly standardize the concrete behavior of administrative personnel and users, thereby making the readers enjoy the right provided by Electronic Reading Room. For those readers who do not conform to the provisions, the administrative personnel of electronic reading room cancel their right of taking advantage of Electronic Reading Room in time.

\section{Strengthen the safety management of open electronic reading room}

The safety management of open electronic reading room in colleges and universities mainly includes network security management, safety management of Internet account, safety management of power source, the safety management of the equipment, etc. Among them, the network security management should work out rational safety measure based on the related legal regulations of the state, which is because the computer virus can not only interfere with normal work of the computers, but also propagate and diffuse virus, which will result in most of the computers in this reading room being damaged, thereby creating the serious consequences. In order to prevent the virus' invasion, administrative personnel should check and kill the virus, establishing the safety records of network, etc. administrative personnel should timely remind the readers of keeping online accounts and its passwords, avoid the loss incurred by password leak. Open electronic reading room should also pay attention to safe use of electricity, configuration independent power supply circuit and install ground wire, server should be equipped with AC stabilities-voltage power or UPS, and check the relevant circuit regularly . On this basis, the management should also strengthen waterproof and anti-theft security management to ensure protection of the readers and all kinds of equipment in electronic reading room. So to speak, only through strengthening the safety management of electronic reading room, can we provide the teachers and students with better working and learning environment.

\section{Conclusion}

To sum up, the Electronic Reading Room of network era of network is becoming more and more important in the library of university and college. We must face and resolve the various problems in the open management of electronic reading room, so as to enhance the capacity of management, thereby creating the safer, more reliable, cleaner and more comfortable high-end open electronic reading room, to better serve the scientific research work, make open electronic reading room truly become the main location for the teaching staff and students to learn, research, and enquire into the bibliographic information.

\section{References}

[1] Qu Hongjun. On the openness of the Electronic Reading Room in the university library during holiday, Journal of study on further education, 2009 (11).

[2] Chen Yang. Discussion on the current problems existing in the management of electronic reading room of university library and corresponding strategy, Journal of reform and openness, 2011 (1).

[3] Du Chun'e. Service and management of the Electronic Reading Room in grass-root public library after free openness, Science Mosaic, 2011 (10).

[4] Huang Ning. The thought about how to strengthen the service after free openness, Journal of agricultural network information, 2012 (6).

[5] Cui Chenguang. Brief talk of supervisory service of the Electronic Reading Room of the public library after free openness, Journal of western library BBS, 2012 (3). 